\title{
Innovation in Pyrolysis Technology for Management of Scrap Tire: a Solution of Energy and Environment
}

\author{
M. Rofiqul Islam, M. Parveen, H. HANIU and M. R. Islam Sarker
}

\begin{abstract}
In this study a new approach in heating system for pyrolysis technology to the recovery of liquid hydrocarbons from solid tire wastes has been developed. A fixed-bed fire-tube heating pyrolysis reactor system has been designed and fabricated considering all of the process parameters. The solid tire wastes were pyrolysed in the reactor under $\mathbf{N}_{2}$ atmosphere. The highest liquid product yield was obtained at a pyrolysis temperature of $475^{\circ} \mathrm{C}$ for feed size of $4 \mathrm{~cm}^{3}$ and vapor residence time of 5 sec. The tire pyrolysis liquids have been characterized including fuel properties, elemental analysis, FT-IR, ${ }^{1} \mathrm{H}-\mathrm{NMR}$, GC-MS analysis and distillation. The fuel properties of the pyrolytic liquids encourage their use as replacements for conventional liquid fuels. The analytical results of the $475^{\circ} \mathrm{C}$ liquids showed that the tire-derived liquids are a complex mixture of $C_{5}-C_{16}$ organic compounds, with a lot of high value light hydrocarbon limonene, single ring alkyl-aromatics and long-chain hydrocarbons. The present research result shows a better solution for energy and environment.
\end{abstract}

Index Terms - Energy, environment, management of scrap tire, pyrolysis technology.

\section{INTRODUCTION}

The energy crisis and environmental degradation are the main problems mankind is facing today. These problems owe their origin to a growing population, rapid industrialization and huge quantities of solid refuse, which are generated daily. To alleviate part of our energy crisis and environmental degradation, it has become imperative to make use of appropriate technologies for the possible recovery of resources from non-conventional sources, like municipal and/or industrial organic wastes, refused plastics, used tires,

Manuscript received February 24, 2010. The work is supported by "Grant-In-Aid for Scientific Research" from the Japan Society for the Promotion of Science under ID No.: P 09094.

Mohammad Rofiqul Islam and Md. Rabiul Islam Sarker are with Department of Mechanical Engineering, Rajshahi University of Engineering \& Technology, Rajshahi-6204, Bangladesh. Phone: +88-0721-750319; E-mail: mrislam1985@yahoo.com

Momtaz Parveen is with Department of Mechanical Engineering, National University Corporation Kitami Institute of Technology,165 Koen-cho, Kitami City, Hokkaido 090-8507, Japan. Phone: +88-157-26-9424; E-mail: m_parveen90@yahoo.com

Hiroyuki HANIU is Department of Mechanical Engineering, National University Corporation Kitami Institute of Technology, 165 Koen-cho, Kitami City, Hokkaido 090-8507, Japan. Telephone: +81-157-26-9224; E-mail: harry@mail.kitami-it.ac.jp etc. The disposal of these organic solid wastes from human activity is a growing environmental problem for modern society, especially in developing countries. The scrap tire is one of the very common and most important hazardous solid wastes all over the world [1].

Pyrolysis basically involves the thermal decomposition of the tire rubber at high temperatures $\left(300-900^{\circ} \mathrm{C}\right)$ in an inert atmosphere. The pyrolysis of solid tire wastes has received increasing attention since the process conditions may be optimized to produce high energy density liquids, char and gases. In addition, the liquid products can be stored until required or readily transportion to where it can be most efficiently utilized. The tire pyrolysis liquids production pathway with their wide range of potential opportunities for heat, chemicals, fuels and electricity applications are indicated by Fig. 1. Tire pyrolysis liquids (a mixture of paraffins, olefins and aromatic compounds) have been found to have a high gross calorific value (GCV) of around 41-44 $\mathrm{MJ} / \mathrm{kg}$, which would encourage their use as replacements for conventional liquid fuels [2-10]. In addition to their use as fuels, the liquids have been shown to be a potential source of light aromatics such as benzene, toluene and xylene (BTX), which command a higher market value than the raw oils [2-4, $8,11,12]$. Similarly, the liquids have been shown to contain monoterpene such as limonene, a high value light hydrocarbon. Limonene has extremely fast growing and wide industrial applications including formulation of industrial solvents, resins and adhesives, as a dispersing agent for pigments, as a fragrance in cleaning products and as an environmentally acceptable solvent [7-9, 13]. It is very common in cosmetic products and also used as flaming combustible liquid.

Pyrolytic char may be used as a solid fuel or as a precursor for activated carbon manufacture [2, 8, 10, 14]. Roy et al. [9] investigated that another potentially important end-use of the pyrolytic carbon black (CBp) may be used as an additive for road bitumen. Some of the previous researcher groups $[2,4$, $8,11,15]$ studied the composition of evolved pyrolysis gas fraction and reported that it contains high concentrations of methane, ethane, butadiene and other hydrocarbon gases with a GCV of approximately $37 \mathrm{MJ} / \mathrm{m}^{3}$, sufficient to provide the energy required by the pyrolysis process.

Very different experimental procedures have been used to obtain liquid products from automotive tire wastes by pyrolysis technology including fixed-bed reactors $[3,4,8$, $11,16-26]$, fluidized-bed pyrolysis units $[6,27,28]$, vacuum pyrolysis units [7, 9, 29-32], spouted-bed reactors [33], etc. A 
number of research works $[3-4,8,16,18,20,24-25,30$, 34-36] have been performed for the effect of reactor temperature on the product yields and product compositions but there have been very limited studies $[6,10]$ in the international literature for the effect of feed size and vapor residence time in tire wastes pyrolysis regime. Dai et al. [6] and Barbooti et al. [10] investigated the effects of feed size and vapor residence time on product yields and compositions

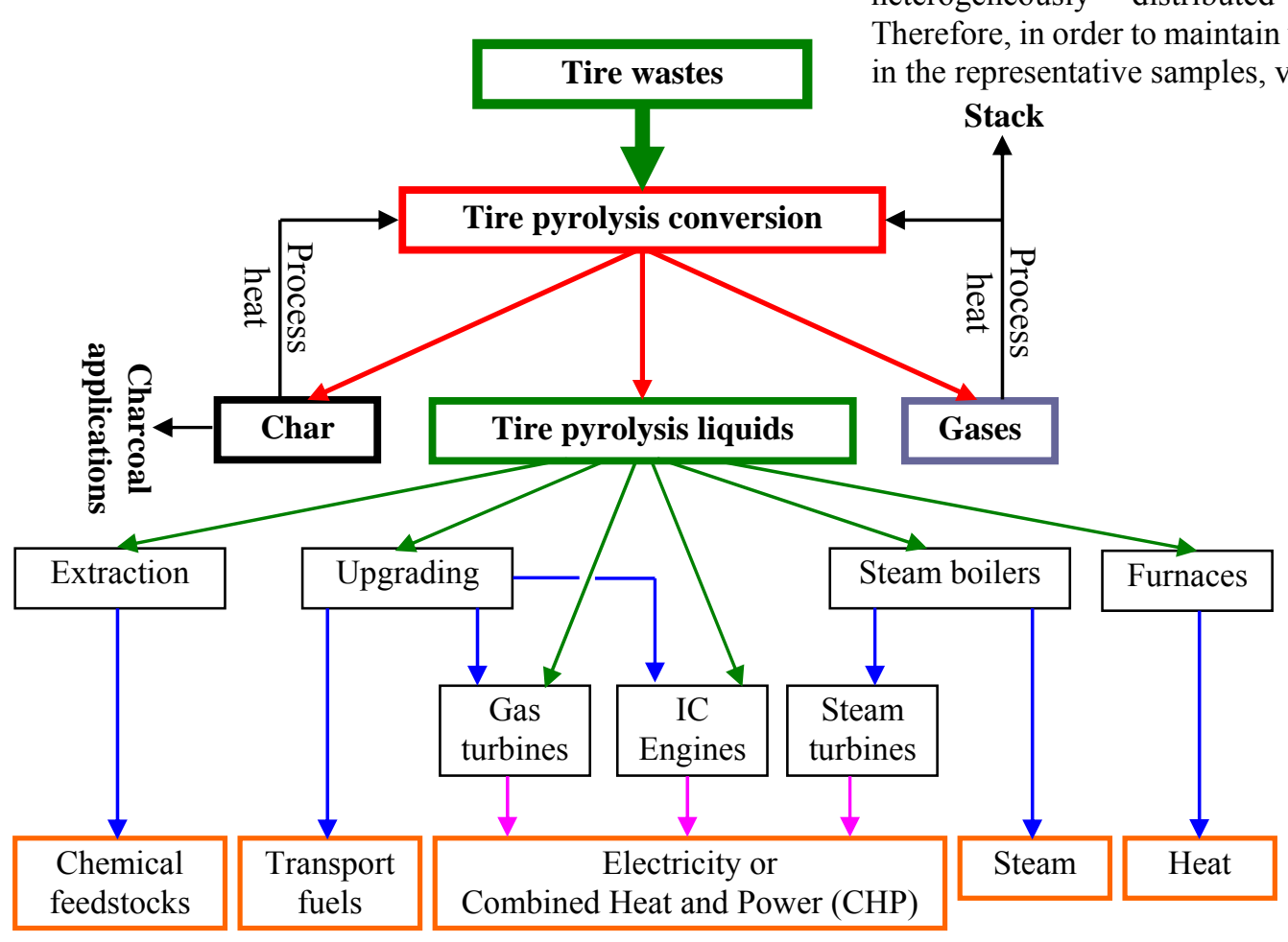

Figure 1: Tire pyrolysis conversion and applications of products

\section{A. Feed materials}

\section{Stack}

\section{MATERIALS AND METHODS}

The "MRF" brands automotive tire waste has been taken into consideration as feedstock throughout the experimental studies that was collected locally from dump site in Rajshahi City Corporation. The main components of tires such as rubber, fillers like carbon black, steel, sulfur, zinc oxide, processing oil, vulcanization accelerators, etc. are heterogeneously distributed over the cross-section. Therefore, in order to maintain uniformity of the components in the representative samples, very same tires were chopped 
a $\mathrm{N}_{2}$ gas cylinder, $\mathrm{N}_{2}$ gas pre-heater, an air compressor, char collection bag and thermocouples. At a distance of $30 \mathrm{~mm}$ from the closed bottom of the reactor, a distributor plate was fitted to support the feedstock. Eight equally spaced stainless steel, $10 \mathrm{~mm}$ diameter fire-tubes containing insulated electric coil of a total capacity $1.60 \mathrm{~kW}$ were fixed inside the reactor. The fire-tubes and pre-heated $\mathrm{N}_{2}$ gas provided uniform heating across the cross-section of the reactor chamber.

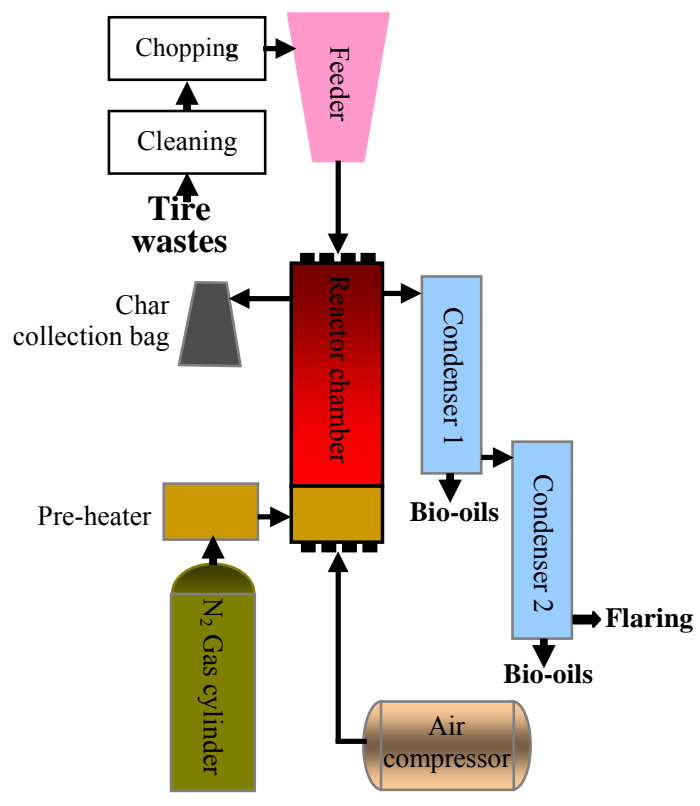

Figure 2: A fixed-bed fire-tube heating pyrolysis system

In each pyrolysis run, by the action of gravity force a quantity of $750( \pm 2.0)$ gm tire sample was supplied from the feeder into the reactor chamber. Then the reactor was purged before experiments by the flow of $\mathrm{N}_{2}$ gas at $4 \mathrm{~L} / \mathrm{min}$ for $5 \mathrm{~min}$ to remove air inside. The pyrolysis experiments were performed by varying the temperature within the range of $375-575^{\circ} \mathrm{C}$ at every $50^{\circ} \mathrm{C}$ for a particular feed size and vapor residence time. The reaction time was $50 \mathrm{~min}$ for every pyrolysis run. Pyrolysis vapor product was passed through two sets of condenser tubes to quench into liquid and then collected into the glass bottles. The uncondensed gases were flared into the atmosphere. The char product was pushed out from the reactor chamber with the aid of compressed air supplied from the air compressor. Char was collected in the char collection bag. Gas weight was determined by subtracting the liquid and char weight from the total weight of feedstock. Once the temperature of maximum liquid yield $\left(475^{\circ} \mathrm{C}\right)$ was selected, additional experiments were conducted at the optimum temperature by varying the feed size and the vapor residence time to find out the optimum process conditions. Before analyzing, the liquid product was centrifuged at $3000 \mathrm{rpm}$ for $15 \mathrm{~min}$ to remove heavy condensate and impurities.

\section{Pyrolytic product liquid analysis}

Pyrolytic liquids obtained under the maximum liquid yield conditions were well mixed and homogenized prior to analysis being made. Some physical properties of pyrolytic liquids: density, viscosity, flash point, pour point and GCV were determined by using the following standard methods: ASTM D189, ASTM D445, ASTM D92, ASTM D97 and
ASTM D240 respectively. Elemental analysis (C, H, N and $\mathrm{S})$ of liquids was determined with an elemental analyzer of model EA 1108, which followed the quantitative "dynamic flash combustion" method. The boiling point range distribution of hydrocarbons in the pyrolytic liquids was determined by using Thermo-gravimetric Analyzer (TGA) of model SHIMADZU TGA-50 according to ASTM D2887-89 standard test method. The sample $(15-20 \mathrm{mg})$ was heated from ambient temperature to $600^{\circ} \mathrm{C}$ at a heating rate of $10^{\circ} \mathrm{C} / \mathrm{min}$ in a high purity helium atmosphere at a flow rate of $100 \mathrm{ml} / \mathrm{min}$. The functional group compositions of the product liquids were analyzed by Fourier Transform InfraRed (FT-IR) spectroscopy. The FT-IR instrument of model PERKIN ELMER FTIR 2000 was used to produce the ir-spectra of the derived liquids. Identification of compounds in pyrolytic liquids was carried out by a gas chromatograph mass spectrometer of model GCMS-QP5000. The analysis was performed on a $60 \mathrm{~m} \times 0.32 \mathrm{~mm}$ capillary column coated with a $1 \mu \mathrm{m}$ film of DB-1. The oven temperature was programmed, $40^{\circ} \mathrm{C}$ hold for $10 \mathrm{~min}$ to $300^{\circ} \mathrm{C}$ at $5^{\circ} \mathrm{C} / \mathrm{min}$ hold for $10 \mathrm{~min}$. Compounds were identified by means of the NIST12 and NIST62 library of mass spectra and subsets HP G1033A. The ${ }^{1} \mathrm{H}$ NMR analyses of pyrolytic liquids were recorded at a frequency of $500 \mathrm{MHz}$ with an instrument of model JEOL A-500 using $\mathrm{CDCl}_{3}$ as solvent.

\section{RESULTS AND DISCUSSION}

\section{A. Pyrolysis product yields}

Three types of products are usually obtained from pyrolysis of tire rubber: solid char, liquid and gas. The product distributions obtained from pyrolysis of prepared representative sample for temperature range of $375-575^{\circ} \mathrm{C}$ at every $50^{\circ} \mathrm{C}$, feedstock size of $4 \mathrm{~cm}^{3}$ and vapor residence time of $5 \mathrm{sec}$ are presented in Table 2 . Table 2 shows that when the temperature increases from 375 to $575{ }^{\circ} \mathrm{C}$, the yield of liquid increases first to a maximum value at $475{ }^{\circ} \mathrm{C}$, and then decreases to a minimum value at $575{ }^{\circ} \mathrm{C}$. The gas yield increases over the whole temperature range, while char yield decreases up to $475^{\circ} \mathrm{C}$ and then remains almost constant. It is apparent that a fairly sharp optimum exists in temperature at which maximum yield of liquid was achieved probably due to strong cracking of the selected tire waste at this temperature. Tire waste sample is not totally decomposed (pyrolysis is not complete) at a temperature less then $475^{\circ} \mathrm{C}$. The thermal decomposition of the sample increases (i.e. solid yield decreases) up to a temperature of $475{ }^{\circ} \mathrm{C}$ and hence increasing the liquid and gas yields. In the temperature range of $475-575^{\circ} \mathrm{C}$, the solid yields are almost equivalent to those of the values obtained by TGA of tire rubber at around 475 ${ }^{\circ} \mathrm{C}$, which are presented elsewhere [38]. The decrease in liquid yields and increase in gas yields above the temperature of $475{ }^{\circ} \mathrm{C}$ are probably due to the decomposition of some oil vapors into permanent gases, and secondary carbonization reactions of oil hydrocarbons into char. The increase in gas yields at higher temperatures is also provided by the char loss reactions. Thus, at higher temperatures the gas yields gradually become dominating. However, $475^{\circ} \mathrm{C}$ seems to be the optimum temperature to obtain liquid products from thermochemical conversion of solid tire waste by pyrolysis technology, since decomposition is complete and the liquid yields become maximized at this temperature. 
Pyrolysis product yields and their distributions over the whole range of temperature depend not only on the feedstock composition and operating temperature used for the experiments, but also on the specific characteristics of the system used, such as size and type of reactor, efficiency of heat transfer from the hot reactor surface to and within the tire mass, feed particle size, vapor residence time, etc. Therefore results from different authors are many times difficult to compare. Moreover sometimes contradictory data can be found in the literature. Some of the former researcher groups $[4,6,25,26]$ have been found very similar in product distributions to those of the present studies i.e. solid yield decreased while gas and liquid yields increased up to an intermediate temperature and then solid yield remained almost constant while gas yield increased and liquid yield decreased with further increase in temperature. The decreases in oil yield with increasing temperature and corresponding increase in gas yield have also been found by other workers [34-36]. The liquid yields obtained in the present study are lower and char yields are higher compared to those of the previous studies $[4,6,8,10,20,26,30,35-36]$ due to mainly the compositional difference (moisture, volatile, fixed carbon and ash content) in tire feeds. In the present study, the liquid yields were equivalent or somewhat higher and char yields were equivalent or somewhat lower than those obtained by other workers $[3,18,24-25,34]$ because of mainly variations in the design of reactors and operating conditions used.

TABLE 2. EFFECT OF REACTOR TEMPERATURE ON THE PRODUCT YIELDS

\begin{tabular}{llllll}
\hline \multirow{2}{*}{$\begin{array}{l}\text { Types of } \\
\text { products }\end{array}$} & \multicolumn{4}{c}{ Product yields at different reactor temperature (wt \%) } \\
\cline { 2 - 6 } & $\mathbf{3 7 5 ^ { \mathbf { 0 } } \mathbf { C }}$ & $\mathbf{4 2 5}^{\mathbf{0}} \mathbf{C}$ & $\mathbf{4 7 5}^{\mathbf{0}} \mathbf{C}$ & $\mathbf{5 2 5}^{\mathbf{}} \mathbf{C}$ & $\mathbf{5 7 5}^{\mathbf{0}} \mathbf{C}$ \\
\hline Liquids & $44 \pm 2.5$ & $48.5 \pm 2$ & $51 \pm 1.5$ & $47 \pm 1.5$ & $43 \pm 2.1$ \\
Solid char & $48.5 \pm 1.5$ & $43 \pm 1.5$ & $40.5 \pm 2.8$ & $40 \pm 1.8$ & $38 \pm 1.8$ \\
Gases & $7.5 \pm 1.4$ & $8 \pm 2.6$ & $8.5 \pm 1.7$ & $13 \pm 2$ & $19 \pm 2.5$ \\
\hline
\end{tabular}

The effect of feed size on product yields under optimum reactor temperature and for a vapor residence time of $5 \mathrm{sec}$ is presented in Table 3 . The table shows that liquid yield first slightly increases up to a value $51 \pm 1.5 \mathrm{wt} \%$ for feed size of $4 \mathrm{~cm}^{3}$ and then decreases for larger feed size while the char yield increases and gas yield decreases through all the piece sizes from 2 to $12 \mathrm{~cm}^{3}$. Smaller feed size provides more reaction surface causes high heating rate and too quick decomposition of the rubber feed occurs. The product oil vapors comparatively get enough time for secondary reaction in the reactor and consequently increase in gas yields and, decrease in liquid and char yields. On the other hand, the heating rate in larger tire feed is low due to its lower thermal

TABLE 3. EFFECT OF FEEDSTOCK SIZE ON PRODUCT YIELDS

\begin{tabular}{lllll}
\hline \multirow{2}{*}{ Types of products } & \multicolumn{4}{l}{ Product yields for different feed size $\mathbf{( w t} \%)$} \\
\cline { 2 - 5 } & $\mathbf{2 \mathbf { c m } ^ { 3 }}$ & $\mathbf{4 \mathbf { c m } ^ { 3 }}$ & $\mathbf{8 \mathbf { c m } ^ { 3 }}$ & $\mathbf{1 2 \mathbf { c m } ^ { 3 }}$ \\
\hline Liquids & $48 \pm 3$ & $51 \pm 1.5$ & $49 \pm 2.4$ & $46 \pm 1.8$ \\
Solid char & $36 \pm 2.6$ & $40.5 \pm 2.8$ & $43 \pm 1.8$ & $47 \pm 2.7$ \\
Gases & $16 \pm 1.3$ & $8.5 \pm 1.7$ & $8 \pm 1$ & $7 \pm 1.5$ \\
\hline
\end{tabular}

conductivity and heat can flow only to a certain depth in the available pyrolysis time compared to almost complete thermal decomposition of the smaller pieces. Thus, the rubber core of the larger pieces becomes carbonized and/or cannot be decomposed completely resulting increase in char yields and decrease in liquid and gas yields. In the present study it may be concluded that the optimum feed size is $4 \mathrm{~cm}^{3}$ for which decomposition of tire pieces is complete and has less possibility of secondary cracking at the optimum reactor temperature and for a vapor residence time of $5 \mathrm{sec}$.

The effects of vapor residence time on gases, char and liquid yields for optimum reactor temperature and for optimum feed size are shown in Table 4. Increasing the flow of $\mathrm{N}_{2}$ gas from cylinder, consequently the vapor residence time inversely decreased, increased the rate of removal of pyrolysis vapor products from tire feed from hot zone. When the vapor residence time increases from $5 \mathrm{sec}$ to $20 \mathrm{sec}$ (i.e. $\mathrm{N}_{2}$ gas flow decreased from 8 to $2 \mathrm{~L} / \mathrm{min}$ ), the liquid and char yields decrease while the gas yield increases slightly. The increase in gas yields with increasing vapor residence time in the present investigation is due to the decomposition of some oil vapor into secondary permanent gases. Primary vapors are first produced from pyrolysis of tire rubber at optimum reactor temperature and the primary oil vapors then degrade to secondary gases within the period of higher vapor residence time, which leads to less oils and more gaseous products. Besides, long contact time between the volatiles and the char leads to another parallel secondary pyrolysis reaction and hence reduces in char yields $[39,40]$. The results of the present work i.e. the decrease in liquid and char yields, and increase in the gas yields with increasing vapor residence time are in good agreement with those of the some published papers $[6,10,41]$.

TABLE 4. EFFECT OF APPARENT VAPOR RESIDENCE TIME ON PRODUCT YIELDS

\begin{tabular}{llll}
\hline \multirow{2}{*}{$\begin{array}{l}\text { Types of } \\
\text { products }\end{array}$} & \multicolumn{3}{l}{ Product yields for different residence time (wt\%) } \\
\cline { 2 - 4 } $\mathbf{5 ~ s e c}$ & $\mathbf{1 0} \mathbf{~ s e c}$ & $\mathbf{2 0} \mathbf{~ s e c}$ \\
\hline Liquids & $51 \pm 1.5$ & $48.5 \pm 2.5$ & $45 \pm 2.7$ \\
Solid char & $40.5 \pm 2.8$ & $38 \pm 2$ & $36 \pm 1.6$ \\
Gases & $8.5 \pm 1.7$ & $13.5 \pm 1$ & $19 \pm 2$ \\
\hline
\end{tabular}

\section{B. Analysis of product liquids}

Fuel properties of the liquids: The fuel properties of the pyrolytic liquids in comparison to commercial automotive No.2 diesel are shown in Table 5. The table shows that density of pyrolytic liquids was found higher than that of the commercial diesel fuel but lower than that of heavy fuel oil $\left(980 \mathrm{~kg} / \mathrm{m}^{3}\right.$ at $\left.20^{\circ} \mathrm{C}\right)$. The viscosity of liquid products from automotive tire wastes was slightly higher than that of the No.2 diesel but too much lower than that of heavy fuel oil $\left(200 \mathrm{cSt}\right.$ at $\left.50^{\circ} \mathrm{C}\right)$. Low viscosity of the liquids of $4.62 \mathrm{cSt}$ at $30^{\circ} \mathrm{C}$ is a favorable feature in the handling and transporting of the liquid. The flash point of the tire-derived liquids is $\leq 30^{\circ} \mathrm{C}$. The flash point is low when compared with petroleum-refined fuels; for example, kerosene has a required minimum flash point of $23^{\circ} \mathrm{C}$, diesel fuel of $55^{\circ} \mathrm{C}$ and light fuel oil $79^{\circ} \mathrm{C}$. The

TABLE 5. BIO-CRUDE OILS PHYSICO-CHEMICAL PROPERTIES

\begin{tabular}{ccc|lcc}
\hline Elements & $\begin{array}{c}\text { Pyro- } \\
\text { oil }\end{array}$ & Diesel & Physical & $\begin{array}{c}\text { Pyro- } \\
\text { properties }\end{array}$ & Diesel \\
\hline $\mathrm{C}$ & 86.52 & $84-87$ & Density $\left(\mathrm{kg} / \mathrm{m}^{3}\right)$ & 943 & $820-860$ \\
$\mathrm{H}$ & 9.35 & $12.8-15.7$ & Viscosity $(\mathrm{cSt})$ & 4.62 & $2.0-4.5$ \\
$\mathrm{~N}$ & 0.53 & $<3000 \mathrm{ppm}$ & Flash point $\left({ }^{\circ} \mathrm{C}\right)$ & $\leq 30$ & $>55$ \\
$\mathrm{~S}$ & 1.30 & $<7000 \mathrm{ppm}$ & Pour point $\left({ }^{\circ} \mathrm{C}\right)$ & -4 & $-40--30$ \\
$\mathrm{Ash}$ & 0.20 & 0.0 & Water $(\mathrm{wt} \%)$ & $\mathrm{N} / \mathrm{A}$ & $\approx 80 \mathrm{ppm}$ \\
$\mathrm{O}$ & 2.10 & 0.0 & pH value & 4.30 & - \\
$\mathrm{H} / \mathrm{C}$ & 1.30 & $1.76-2.24$ & GCV $(\mathrm{MJ} / \mathrm{kg})$ & 41.60 & $44-46$ \\
\hline
\end{tabular}

low flash points of the tire-derived liquids are not surprising since the product liquids represent un-refined liquids with a mixture of components having a wide distillation range [38]. The pour point of the tire-derived liquids is comparatively 
low compared to the automotive diesel fuel but the laboratory experience of the authors of the present paper shows that it is not problematic even at $5^{\circ} \mathrm{C}$. The $\mathrm{pH}$ value of the pyrolytic liquids is 4.30 , which is in weak acidic nature. It is found that there is very little contamination of the liquids with metals (V, Mn, Mg, Ba, Ni, Ti, Cu, Cr, Cd, Co, Fe, Al, and Zn) [9], and does not contaminate with glass and PET plastic and/or other plastics. The $\mathrm{pH}$ value of soft drinks like Cola and Pepsi of Coca Cola company is 2.5 and they use PET plastic bottles for its storage and handlings. Thus, storage and handling of the liquids are little problematic for industrial usage.

Chemical composition of the liquid products: The average chemical composition of the pyrolytic liquid has been analyzed as $\mathrm{CH}_{1.30} \mathrm{O}_{0.018} \mathrm{~N}_{0.005}$. Obviously, the product liquid has a small amount of oxygen content, with a higher $\mathrm{H} / \mathrm{C}$ ratio than that of solid tire wastes (Table 1). The $\mathrm{H} / \mathrm{C}$ ratio of the pyrolytic liquids (Table 5) indicates that such oils are a mixture of aliphatic and aromatic compounds [3]. The $\mathrm{C} / \mathrm{H}$ ratio is somewhat higher than that found for petroleum derived fuels. The long chain diesel like structure attributes to high $\mathrm{C} / \mathrm{H}$ ratio as reflected by very high $\mathrm{GCVs}$, comparable to fuel oil and diesel, as well as indicates the high miscibility with the diesel fuel as per like dissolves like principle. The nitrogen content is however, rather higher than the No.2 diesel but similar to a heavy fuel oil in the range of $0.3-0.5 \mathrm{wt} \%$. The sulphur content in the derived liquids is significantly high compared to the legislation requirements for different countries to safe environment [42]. The important requirements for diesel fuel are its ignition quality, viscosity, water, sediment and sulfur contents. Therefore, the pyrolytic liquids require preliminary treatments such as decanting, centrifugation, filtration, desulphurization and hydrotreating to be used as fuels. The treated pyrolysis oil could be used directly as fuel oils or blended with diesel fuels, which will reduce the viscosity and, increase the $\mathrm{pH}$ value and flash point of the resulting blends. Consequently, the atomization will be improved, ensuring a complete burnout of the fuel [9]. Based on its fuel properties, tire-derived pyrolytic liquids may be considered a valuable component for use with automotive diesel fuels. Moreover, the liquids may be directly used as fuels for industrial furnaces, power plants and boilers.

The FT-IR is not the most appropriate analytical tool to determine saturated, aromatic and polar components. Nevertheless, it allows functional group analysis to reveal the chemical properties of the liquids. The FT-IR analysis for pyrolytic liquids derived from automotive tire waste has been carried out and the results obtained from the transmittance spectrums are presented in Table 6 . The data shows therefore that the present liquids contain mainly aliphatic and aromatic compounds.

TABLE 6. FT-IR FUNCTIONAL GROUPS AND INDICATED COMPOUNDS

\begin{tabular}{lll}
\hline $\begin{array}{l}\text { Frequency } \\
\text { range }\left(\mathbf{c m}^{-\mathbf{1}}\right)\end{array}$ & Groups & Class of compounds \\
\hline $3095-3005$ & C=C stretching & Alkenes \\
$3000-2800$ & C-H stretching & Alkanes \\
$1680-1620$ & C $=$ C stretching & Alkenes \\
$1600-1525$ & Carbon-carbon stretching & Aromatic compounds \\
$1520-1220$ & C-H bending & Alkanes \\
$1035-830$ & C $=$ C stretching & Alkenes \\
$825-650$ & C-H out of plane bending & Aromatic compounds \\
\hline
\end{tabular}

The ${ }^{1} \mathrm{H}$ NMR has been performed for the pyrolytic liquids and the hydrogen distribution obtained from the ${ }^{1} \mathrm{H}$ NMR spectrums is given in Table 7, indicating that no aliphatic carbon is still bound to oxygen (peaks in 3.3-4.5 ppm chemical shift range). Clearly, the main structure of the liquids seems to be aliphatic bonded to aliphatic only (0.4-1.8 ppm chemical shift range), and as a result the carbon aromaticity of the liquids is comparatively low. The alkanes and long alkyl spectrums are probably largely derived from solid tire wastes.

TABLE 7. ${ }^{1} \mathrm{H}$ NMR RESULTS FOR THE PRODUCT LIQUIDS

\begin{tabular}{lcl}
\hline Type of hydrogen & $\begin{array}{l}\text { Chemical } \\
\text { shift (ppm) }\end{array}$ & $\begin{array}{l}\text { Mol\% of } \\
\text { total } \mathbf{H}_{\mathbf{2}}\end{array}$ \\
\hline Aromatic & $9.0-6.5$ & 21.33 \\
Phenolic (OH) or olefinic proton & $6.5-4.5$ & 12.54 \\
Aliphatic adjacent to oxygen/hydroxyl group & $4.5-3.3$ & -- \\
Aliphatic adjacent to aromatic/alkene group & $3.3-1.8$ & 8.51 \\
Other aliphatic (bonded to aliphatic only) & $1.8-0.4$ & 57.62 \\
\hline
\end{tabular}

GC-MS analysis was carried out with the pyrolysis liquids obtained at $475^{\circ} \mathrm{C}$ temperature for feed size of $4 \mathrm{~cm}^{3}$, and apparent vapor residence time of $5 \mathrm{sec}$ to get an idea about the nature and type of compounds of such liquids. The NIST search software was used to analyze the peaks provided by the chromatogram, from which more than the half was not properly identified. The peaks whose identification results of mach quality $\geq 90 \%$ were considered valid and their tentative assignments were confirmed, where in agreement the published GC-MS data for similar products [3, 16, 17].

Tables 8 shows the tentative compounds assigned and their percentage area compared to the total area of the chromatogram, which give an estimate for their relative concentration in the pyrolytic liquids. It can be seen from GC-MS results that, tire pyrolysis liquids are a very complex mixture, containing many aliphatic and aromatic compounds with their total concentration of $43.04 \%$, and $29.15 \%$, respectively. The GC-MS results support well the results obtained from FT-IR [Table 6] and ${ }^{1} \mathrm{H}$ NMR [Table 7] analyses. The aliphatic compounds are mainly of alkane and alkene groups but the second is predominant. The aromatic compounds are only single ring alkyl aromatics. In addition to the main hydrocarbons, small percentage of nitrogen and oxygen-containing compound, 1,2,3,4-Tetrahydro-5-nitro -naphthalene $\left(\mathrm{C}_{10} \mathrm{H}_{11} \mathrm{NO}_{2}\right)$; oxygen, and sulphur-containing compound,1-Phenyl-2-ethylprop-1-ene-(1-3)sultine

$\left(\mathrm{C}_{11} \mathrm{H}_{12} \mathrm{O}_{2} \mathrm{~S}\right)$; and chlorine-containing compound, 1,7-Dichloroheptane $\left(\mathrm{C}_{7} \mathrm{H}_{14} \mathrm{Cl}_{2}\right)$ were also identified. Other oxygen-containing compounds in the form of acid and alcohol are also present in the automotive tire derived liquids. The most abundant compound present in the pyrolytic liquids is limonene whose total concentration is $11.11 \%$. It is known that limonene is the most important product form pyrolysis of polyisoprene [7, 24]. Besides formation of limonene depends on operating conditions such as pyrolysis pressure, temperature, vapor residence time and sample size. Pakdal et al. [7] studied in detail for optimum operating conditions for the production of limonene from used tire by vacuum pyrolysis. They reported that low pyrolysis pressure and temperature, and short vapor residence time increase the limonene yields. 
TABLE 8. TENTATIVE GC/MS CHARACTERIZATION OF AUTOMOTIVE TIRE-DERIVED PYROLYTIC LIQUIDS

\begin{tabular}{|c|c|c|}
\hline Retention time (min) & Tentative assignment & Peak area (\%) \\
\hline 7.75 & 2-Methyl-1,3-butadiene & 2.91 \\
\hline 8.18 & 2-Methyl-2-butene & 2.96 \\
\hline 9.95 & 2,3-Dimethyl-2-butene & 0.18 \\
\hline 11.66 & 4-Methyl-2-pentene & 0.66 \\
\hline 12.90 & 2,3-Dimethyl-1,3-butadiene & 1.37 \\
\hline 13.83 & Benzene & 5.97 \\
\hline 14.95 & Cyclooctene & 0.20 \\
\hline 16.09 & 3-Heptene & 0.59 \\
\hline 17.32 & (Z)-3-Undecen-1-yne & 0.35 \\
\hline 17.87 & (Z)-3-Dodecan-1-yne & 0.19 \\
\hline 19.25 & 2-Propenylidene-cyclobutene & 3.03 \\
\hline 19.39 & Toluene & 5.82 \\
\hline 19.66 & 1,7-Dichloroheptane & 0.95 \\
\hline 20.96 & (Z)-3-Decen-1-yne & 0.16 \\
\hline 21.65 & 1,1-Dimcyclopropyl-ethylene & 0.24 \\
\hline 22.33 & 4-Methyl-1,4-heptadiene & 0.37 \\
\hline 22.75 & 7-Methyl-3,4-octadiene & 1.08 \\
\hline 24.35 & $p$-Xylene & 7.29 \\
\hline 24.47 & $m$-Xylene & 1.56 \\
\hline 24.60 & $o$-Xylene & 3.60 \\
\hline 25.35 & 1,7-Octadiyne & 2.34 \\
\hline 25.38 & 3,3-Dimethyl-4-pentenyl-benzene & 3.68 \\
\hline 26.80 & (E)-4-Hexadecen-6-yne & 0.42 \\
\hline 27.37 & 6,6-Dimethyl-2-methylene-bicyclo 3.1.1 heptane & 0.68 \\
\hline 27.70 & Decahydro-1,1,4,7-tetramethyl-1H-cyclopropeazulene & 0.71 \\
\hline 27.98 & Octahydro-1,4,9,9-tetramethyl-1H-3a,7-methanoazulene & 0.50 \\
\hline 28.54 & 5,9-Tetradecadiyne & 3.28 \\
\hline 29.51 & 7,11-Dimethyl-3-methylene-1,6,10-dodecatriene & 2.11 \\
\hline 29.77 & 3,7,11-Trimethyl-1,3,6,10-dodecatetraene & 1.93 \\
\hline 30.03 & 2-Methyl-3,5-dodecadiene & 1.99 \\
\hline 31.74 & Limonene & 9.17 \\
\hline 31.78 & Limonene & 1.94 \\
\hline 31.95 & (Z)-3-Heptadecen-5-yne & 0.73 \\
\hline 32.22 & 1-Propynyl-benzene & 1.23 \\
\hline 32.38 & 8-Methylene-dispiro 2.0.2.5 undecane & 0.98 \\
\hline 33.56 & 2,5-Octadecadiynoic acid & 1.84 \\
\hline 34.30 & 4,4-Dimethyl-1-(2,7-octadienyl)-cyclobutene & 0.44 \\
\hline 34.44 & 1,5-Dimethenyl-3-methyl-2-methylene-cyclohexane & 0.25 \\
\hline 34.93 & Caryophyllene & 0.32 \\
\hline 35.15 & 3-Methylene-spiro bicyclo 6.1 .0 nonane-9,1-cyclopentane & 0.27 \\
\hline 35.23 & (E,E)-12-Methyl-1,5,9,11-tridecatetraene & 0.15 \\
\hline 35.70 & (Z)-3-Heptadecen-5-yne & 0.54 \\
\hline 36.12 & 1,2,3,4-Tetrahydro-5-nitro-naphthalene & 0.67 \\
\hline 36.35 & 1-Phenyl-2-ethylprop-1-ene-(1-3)sultine & 0.34 \\
\hline Total identified & & 75.99 \\
\hline
\end{tabular}

The present pyrolytic liquids as well as the previous studies [2, 3, 17] also contain small amount of oxygenated, nitro-oxygenated and sulphurated compounds. The oxygenated compounds are probably derived from the thermal degradation of oxygenated components of the tire, such as stearic acid, extender oils, etc. The presence of 2-mercaptobenzothiozoe, benzothiozolyl disulphide, etc.
The presence of chorine containing compound, 1,7-Dichloroheptane $\left(\mathrm{C}_{7} \mathrm{H}_{14} \mathrm{Cl}_{2}\right)$ in the present pyrolytic liquids may be explained by thermal decomposition of sulphur monochloride, which sometime is used as vulcanizing agent with main vulcanizing agent, sulphur.

The greater non-identified peaks in the chromatogram are due to the presence of heavier and more complex products, which are produced during pyrolysis and hence are more difficult to identify. 


\section{BOILING POINT DISTRIBUTIONS OF PYROLYTIC LIQUIDS}

The boiling point distributions of hydrocarbons in the tire-derived pyrolytic liquids obtained at the temperature of $475^{\circ} \mathrm{C}$ are presented in Table 9. For comparison purpose, the simulated distillation results of commercial gasoline and diesel fuel are also presented in Table 9. The data shows that the pyrolytic liquids have a wide boiling point range. The table shows that about $35 \%$ of pyrolytic liquids can be distilled at a temperature of $170^{\circ} \mathrm{C}, 15 \%$ between $160-200^{\circ} \mathrm{C}$ and $45 \%$ between $200-350^{\circ} \mathrm{C}$, which correspond to the limit boiling points of light naphtha, heavy naphtha and middle

TABLE 9: BOILING POINT DISTRIBUTION OF THE PYROLYTIC LIQUIDS

\begin{tabular}{cccc}
\hline $\begin{array}{c}\text { Fractional } \\
\text { volume (\%) }\end{array}$ & $\begin{array}{c}\text { Pyrolytic } \\
\text { liquid }\end{array}$ & Gasoline & $\begin{array}{c}\text { Commercial } \\
\text { diesel }\end{array}$ \\
\hline 10 & 105 & 50 & 195 \\
20 & 132 & 55 & 220 \\
30 & 153 & 60 & 240 \\
40 & 173 & 68 & 245 \\
50 & 205 & 80 & 250 \\
60 & 229 & 90 & 260 \\
70 & 249 & 100 & 270 \\
80 & 282 & 120 & 300 \\
90 & 316 & 140 & 350 \\
100 & 572 & 172 & 400 \\
\hline
\end{tabular}

distillate, respectively. Laresgoiti et al. [3] reported that in their car tire-derived pyrolitic liquids, light naphtha, heavy naphtha and middle distillate were $20 \%, 10 \%$ and $35 \%$, respectively whereas Ucar et al. [16] found the corresponding values in their truck tire derived pyrolytic liquids as $40 \%$, $\approx 15 \%$ and $\approx 45 \%$. The presence of higher amount of middle distillates is the significance of probable wider applications of the pyrolytic liquids as diesel fuels and heating oils. The distillates from present tire-derived liquids are very similar to those of Ucar et al. [16]'s truck tire derived liquids because of the major compounds identified by GC/MS in both studies are almost similar. The selected tire-derived pyrolytic liquids contain lighter compounds compared to those of Laresgoiti et al. [3]'s car tire-derived liquids. This is due to the presence of larger amount of aromatics of higher boiling points in their car tire oils. From Table 9, it can be seen that the pyrolytic liquid fractions under boiling point range of 150 to $350^{\circ} \mathrm{C}$, which is about $70 \%$ of total volume, is important to take into consideration to be usable as diesel fuels. It can also be realized from Table 9 that the tire pyrolysis liquid fractions have comparatively lighter products than the commercial diesel fuels, because of the boiling point distribution for the liquids up to $350^{\circ} \mathrm{C}$ is lower than that of commercial diesel. Thus, the tire liquid fractions within the boiling point range of $150-350^{\circ} \mathrm{C}$ may be atomized well and hence it is possible to initiate the combustion at a lower temperature. On the contrary, above $350^{\circ} \mathrm{C}$ the tire-derived pyrolytic liquids have some heavier products than the commercial diesel fuels and this fraction probably contain polycyclic aromatics [3], which are restricted in legislations requirements to be used as automotive fuels but less restricted as heating oils.

\section{CONCLUSIONS}

The research findings of the studies show that fixed-bed fire-tube heating pyrolysis is a good option for production of bio-crude oils from solid tire wastes. The optimum liquid yields conditions for the fixed-bed fire-tube heating reactor system are: operating temperature $475^{\circ} \mathrm{C}$, feed size $4 \mathrm{~cm}^{3}$ and apparent vapor residence time $5 \mathrm{sec}$. The fuel properties of the pyrolysis liquids such as density, viscosity, GCV, carbon and hydrogen contents are found almost comparable to those of the commercial automotive diesel fuels but higher sulphur content and lower flash point are problematic. The pyrolytic liquids abundantly contain olefins, specially limonene and light aromatics, which have higher market values as chemical feedstock than their use as fuels.

\section{ACKNOWLEDGMENT}

The authors would like to express their sincere gratitude and thanks to the Japan Society for the Promotion of Science (JSPS) for proving a sufficient amount of "Grant-In-Aid for Scientific Research" (Tokubetsu Kenkyuin Shorei-hi) to cover the research-related expenses under ID No.: P 09094.

\section{REFERENCES}

[1]

385-99.

[7] 91-107.

[8] A.M. Cunliffe, P.T. Williams, J. Anal. Appl. Pyrolysis 44 (1998) 131-52.

[9] C. Roy, A. Chaala, H. Darmstandt, J. Anal. Appl. Pyrolysis 51 (1999) 201-21.

[10] M.M. Barbooti, T.J. Mohamed, A.A. Hussain, F.O. Abas, J. Anal. Appl. Pyrolysis 72 (2004) 165-170.

[11] P.T. Williams, A.J. Brindle, J. Anal. Appl. Pyrolysis 67 (2003) $143-64$.

[12] P.T. Williams, A.J. Brindle, Fuel 82 (2003) 1023-1031.

[13] H. Pakdel, C. Roy, H. Aubin, G. Jean, S. Coulombe, Environ. Sci. Technol. 9 (1992) 1646.

[14] A.M. Cunliffe, P.T. Williams, Energy \& Fuels 13 (1999) 166-75.

[15] F. Murena, E. Garufi, R.B. Smith, F. Gioia, Journal of Hazardous Materials 50 (1996) 79-98.

[16] S. Ucar, S. Karagoz, A.R. Ozkan, J. Yanik, Fuel 84 (2005) 1884-92.

[17] M. Kyari, A. Cunliffe, P.T. Williams, Energy \& Fuel 19 (2005) 1165-73.

[18] M.F. Laresgoiti, I. de Marco, A. Torres, B.M. Caballero, M.A. Cabrero, M.J. Chomón, J. Anal. Appl. Pyrolysis 55 (2000) 43-54.

[19] I. de. Macro, M.F. Laresgoiti, M.A. Cabrero, A. Torres, M.J. Chomón, B.M. Caballero, Fuel Proc. Technol. 72 (2001) 9.

[20] P.T. Williams, S. Besler, D.T. Taylor, Fuel 69 (1990) 1474-82

[21] A. Napoli, Y. Soudais, D. Lecomte, S. Castillo, J. Anal. Appl. Pyrolysis 40-41 (1997) 373.

R. Murillo, E. Aylon, M.V. Navarro, M.S. Callen, A. Aranda, A.M. Mastral, Fuel Proc. Technol. 87 (2006) 143-47.

[23] M.R. Islam, H. Haniu, M.R.A. Beg, Journal of Environment and Engineering 2(4) (2007) 681-95.

[24] A.M. Mastral, R. Murillo, M.S. Callen, T. Garcia, C.E. Snape, Energy \& Fuels 14(4) (2000) 739-744. 
[25] Y.M. Chang, Resour. Conserv. Recy. 17 (1996) 125-39

[26] M.N. Islam, M.N. Islam, M.R.A. Beg, International Energy Journal 5(1) (2004) 11-18.

[27] R.B. Zailani, Fluidized-bed Pyrolysis of Organic Solid Waste, Mech Eng. Thesis, Universiti Teknologi Malaysia, Malaysia, 1995.

[28] W. Kaminsky, C. Mennerich, J. Anal. Appl. Pyrolysis 58-59 (2001) 803-11.

[29] S. Mirmiran, H. Pakdel, C. Roy, J. Anal. Appl. Pyrolysis 22 (1992) 205.

[30] C. Roy, A. Rastegar, S. Kaliaguine, H. Darmstadt, Plast. Rubber Compos. Proc. Appl. 23 (1995) 21.

[31] B. Benallal, C. Roy, H. Pakdel, S. Chabot, M.A. Poirier, Fuel 74(11) (1995) 1589.

C. Roy, B. Labrecque, B. de Caumia, Resour. Conserv. Recy. 4 (1990) 203.

R. Aguado, M. Olazar, M. Arabiourrutia, S. Alvarez, J. Bilbao, In:

[33] Proceedings of the VIII Congreso de Ingenier and Ambiental PROMA'03, Bilbao, Spain, 2003.

W. Kaminsky, H. Sinn, Pyrolysis of plastic waste and scrap tires using a fluidized bed process, in: J.L. Jones, S.B. Radding (Eds.),

[34] Thermal Conversion of Solid Wastes and Biomass, ACS Symposium Series 130, American Chemical Society Publishers, Washington DC, 1980.

[35] A. Lucchesi, G. Maschio, Conserv. Recycl. 6(3) (1983) 85-90.

[36] P.T. Williams, S. Besler, D.T. Taylor, Proc. Inst. Mech. Eng. 207 (1993) 55-63.

[37] Islam, M. R, Haniu, H. and Kim, S.I., Journal of Fluid Science and Technology 2008;3(7):826-837.

Islam, M. R. Fixed-bed fire-tube heating pyrolysis of solid tire wastes available in Bangladesh for production of liquid fuels and chemicals.

[38] PhD Thesis, National University Corporation Kitami Institute of Technology, Japan, September 2008.

[39] A.V. Bridgwater, J. Anal. Appl. Pyrolysis 51 (1999) 3-22, [and references therein].

D. Brown, Continuous ablative regenerator system. In A.V.

[40] Bridgwater, E.N. Hogan editors. Bio-oil Production and Utilization. CPL Press; 1996:96-100

R. Cypres, B. Bettens, in pyrolysis and gasification: G.L. Ferrero, K.

[41] Maniatis, A. Buekens, A.V. Bridgwater, Eds.; Elsevier Applied Science: London, 1989.

L. Kiuru, Worldwide fuel quality trends-focus on Asia, in [42] proceedings of Better Air Quality in Asia and Pacific Rim Cities, Hong Kong Convention and Exhibition Center, Hong Kong, 2002. 